\section{REFERENCES}

1. Kupisiewicz, Cz. (2006). Projekty reform edukacyjnych $w$ Polsce [Projects of educational reforms in Poland]. Warszaw: PWN, 154 p. [in Polish].

2. Kwiatkowska, H. (1988). Nowa orientacja w ksztatceniu nauczycieli [A new orientation in teacher education]. Warszaw: PWN, 358 p. [in Polish].

3. Pawłowski, K. (2009). Raport o stanie kultury w obszarze szkolnictwa artystycznego [Report on the state of culture in the field of artistic education]. Warsaw:
Ministry of Culture and National Heritage, 72 p. [in Polish]. 4. Times Higher Education World University Rankings [Electronic resource]. Access mode: https:// www.timeshighereducation.com/world-universityrankings/2017/world-ranking. [in English].

5. USTAWAz dnia 27 lipca 2005 r. Prawo o szkolnictwie wyższym [ACT of 27 July 2005. Law on Higher Education] [Electronic resource]. Access mode: https://amu.edu.pl/ data/assets/pdf_file/0003/29226/D20051365Lj.pdf. [in Polish].

Стаття надійшла до редакції 13.12.2018

УДК: 316.613:378.2:1:001.891

DOI:

Вікторія Меняйло, кандидат фізико-математичних наук, доцент, докторант кафедри педагогіки і психологї освітньої діяльності Запорізького національного університету

\title{
РЕФЛЕКСИВНО-ПЕРСПЕКТИВНИЙ КОМПОНЕНТ ГОТОВНОСТІ МАЙБУТНЬОГО ДОКТОРА ФІЛОСОФІї ДО ДОСЛІДНИЦЬКО-ІННОВАЦЙНОӤ ДІЯЛЬНОСТІ: СУТНІСТЬ І СТРУКТУРА
}

У даній статті показано, що рефлексивно-перспективний компонент готовності до дослідницькоінновачійної діяльності може бути реалізований у чотирьох аспектах, зокрема у прочесі діяльності у доктора філософії виникає потреба щзодо: творчого переосмислення свого психічного стану та оиінки своєї поведінки, суджень, вчинків (особистісний аспект); розуміння того, як його сприймають студенти, колеги, партнери, адміністрація; а також усвідомлення мотивів, иілей, дій тихлюдей, з якими він співпрацює (комунікативний аспект); необхідності аналізу, планування та координаиії спільних дій з іниими суб'єктами діяльності (корпоративний аспект); осмислення і переосмислення сутності та змісту своєї дослідницько-інноваційноі діяльності, ї̈ пріоритетних иілей та завдань, прийняття рімення щодо ї̈ реорганізації та вдосконалення (інтелектуальний аспект).

Ключові слова: готовність до досліднищько-інноваційної діяльності; доктор філософії; рефлексивноперспективний компонент готовності.

Puc. 1. Лim. 12.

Viktoriya Menyaylo, Ph.D.(Physical and Mathematical Sciences), Associate Professor, Doctorale Student of the Pedagogy and Psychology of Educational Activity Department Zaporizhzhya National Universite

\section{REFLECTIVE AND PERSPECTIVE COMPONENT OF READINESS OF THE FUTURE DOCTOR OF PHILOSOPHY FOR THE RESEARCHAND INNOVATION ACTIVITY}

This article describes the essence and structure of the reflexive-perspective component of the readiness of future PhD's for the research and innovation activity. It has been shown, that this component can be implemented into four aspects: intellectual and personal in relation to individual activities, as well as communicative and corporate in relation to collective activities. This means that in the process of conducting research and innovation activitiy, which tends to occur in new, uncertain conditions and accompanied by the emergence of non-standard situations, etc., the PhD needs a creative rethinking of his mental state and his behavior, judgments, actions (personality aspect), understanding of how it is perceived by students, colleagues, partners, administration; as well as awareness of the motives, goals, actions of the people with whom he cooperates (the communicative aspect); the need for analysis, planning and coordination of joint actions with other actors (corporate aspect), comprehension and rethinking of the essence and content of its research and innovation activity, its priority goals and tasks, decision-making on its reorganization (intellectual aspect). As a result, he has to perform the following functions: "I am a controller", "I am a communicator", "I am a coordinator", "I am a professional". Thus, the reflexiveperspective component of readiness of future doctor of philosophy for the research and innovation activity involves the understanding of itself as a subject of activity, its features, abilities, actions and how it is perceived by others; rethinking the goals, process and results of its activities, correcting errors and finding ways to improve it; an idea of the inner world of other people and an analysis of the causes of their actions; awareness of the process of joint 
activities of participants in the collective process and the adoption of appropriate decisions for its coordination and successful implementation, as well as the desire for continuous self-improvement and professional growth.

Keywords: readiness for the research and innovation activity; a doctor of philosophy; the reflexive-perspective component of the readiness.

П остановка проблеми. В умовах євроінтеграційних прагнень України великим кроком у напрямку наближення системи української освіти до європейських норм стало запровадження третього рівня вищої освіти, на якому ведеться підготовка докторів філософії, що здійснюється за освітньо-науковими програмами, які передбачають не лише індивідуальну роботу над дисертаційним дослідженням, але й повноцінний навчальний процес, який має на меті підготувати майбутнього доктора філософії до професійної та дослідницько-інноваційної діяльності [7]. У зв'язку 3 цим у педагогічній науці постає питання розробки концепції та моделі такої підготовки, зокрема формування готовності майбутніх науковців до дослідницько-інноваційної діяльності, а відповідно, i визначення компонентів структури цієї готовності.

Аналіз основних досліджень і публікацій. Як показав проведений аналіз літератури, на сьогоднішній день питання змісту освітньої складової підготовки наукових, науковопедагогічних кадрів досліджують С. Сисоєва, I. Регейло (зарубіжний досвід підготовки докторів філософії та шляхи його впровадження в Україні); Н. Сидорчук, І. Хом'юк (формування психологопедагогічної компетентності доктора філософії); О. Спірін, Ю. Носенко, А. Яцишин (зміст підготовки наукових кадрів 3 інформаційнокомунікативних технологій в освіті). Формування готовності майбутнього доктора філософії до дослідницько-інноваційної діяльності та розкриття компонентів структури цієї готовності до цього часу не було предметом наукового педагогічного дослідження.

Метою статті $€$ розкриття сугності і структури рефлексивно-перспективного компоненту готовності майбутнього доктора філософії до дослідницько-інноваційної діяльності.

Виклад основного матеріалу дослідження. Рефлексія (від лат. reflexio - обернення назад) це поняття, яке виникло у філософії та трактується в ній як "самосвідомість і самопізнання, співвідносність елементів мислення і дійсності" $[11,547]$. Класична установка "Пізнай самого себе" веде свій початок ще $з$ античних часів. С. Степанов та I. Семенов, здійснюючи аналіз філософських джерел, наводять такі визначення рефлексії як:

- здатність розуму обертати свій “погляд” на себе;
- мислення про мислення;

- аналіз знання з метою отримання нового знання або перетворення знання неявного узнання явне;

- самоспостереження за станом розуму або душі;

- вихід 3 поглинання життєдіяльністю;

- дослідницький акт, що спрямовується людиною на саму себе [10, 34].

Об'єктом психологічної науки рефлексія стає упершій чверті XX століття, починаючи зА. Буземана, який одним із перших виділив дослідження щодо рефлексії і самосвідомості в особливу область і назвав ії психологією рефлексії $[2,228]$. За його визначенням, рефлексією є будь-яке перенесення переживання індивіду з зовнішнього світу на самого себе $[2,228]$. Вивченню рефлексії як психологічного феномену присвячені роботи Б. Ананьєва, П. Блонського, Л. Виготського, С. Рубінштейна та ін. Наразі поняття "рефлексія" застосовується у психології для пояснення різних експериментальних фактів при дослідженні таких феноменів як особистість, свідомість, пам'ять, мислення, спілкування тощо.

Для розкриття змісту рефлексивноперспективного компоненту дослідницькоінноваційної діяльності доктора філософії вважаємо за доцільне скористатися типологізацією рефлексії, запропонованою у роботі “Типы и функции рефлексии в организации принятия решения оператором", автори якої на підставі аналізу результатів численних психологічних досліджень виділили чотири типи рефлексії: кооперативний, комунікативний, особистісний, інтелектуальний $[9,127$ - 129], перші два з яких характеризують колективні, а інші два індивідуальні форми діяльності.

Кооперативний тип рефлексії пов'язаний 3 необхідністю майбутньому доктору філософії вміти аналізувати, проектувати та координувати спільну 3 колегами та (або) студентами дослідницько-інноваційну діяльність, ухвалювати відповідні рішення задля її успішного виконання, розподіляти групові ролі учасників та планувати їхні дії у колективному процесі. Отже, цей тип рефлексії виконує функцію планування та координації спільних дій суб'єктів дослідницькоінноваційної діяльності. Погоджуємося 3 М. Марусинець, що планування як процес, що передбачає прогнозування можливих напрямків перебігу подій та результатів діяльності, 
грунтується на випереджувальному відображенні і $є$ неможливим без рефлексивних процесів [5, 42]. Г. Щедровицький розглядає таку рефлексію як вивільнення суб'єкта з процесу діяльності, тобто вихід його у позицію, зовнішню по відношенню до цієї діяльності [12, 12 - 28].

Комунікативний тип рефлексії представляє, за А. Бодулевим, специфічну якість пізнання людини людиною [1, 42 - 43], яка проявляється “як роздум за іншу особу, здатність розуміти, що думають інші особи” [8, 142], а також усвідомлення індивідом того, як його сприймають і оцінюють інші індивіди або спільноти. Таким чином, рефлексивний компонент у комунікативному аспекті характеризується, 3 одного боку, розумінням доктора філософії того, як його сприймають студенти, колеги, партнери, адміністрація; а з іншого - власною спроможністю усвідомлювати мотиви, цілі, дії тих людей, з якими він співпрацює; осмислювати результати їхньої або спільної з ними дослідницько-інноваційної діяльності 3 метою виявлення та усунення помилок або, навпаки, запозичення позитивного досвіду для використання або евристичного перетворення його у процесі створення інновацій. Таким, чином, констатуємо, що цей тип рефлексії виконує аналітичну функцію щодо діяльності і думок інших людей.

У процесі наступного, особистісного типу рефлексії доктор філософії сам виступає об'єктом власного дослідження, здійснюючи при цьому аналіз свого психічного стану та даючи оцінку своїй поведінці, судженням, вчинкам. Основними психологічними якостями особистості тут виступають самокритичність, самооцінка, самоконтроль, самоаналіз як критичне переосмислення власного досвіду $[6,4]$. Отже, у даному випадку рефлексія здійснює контрольну функцію. Підтвердженням нашої думки є і позиція М. Марусинець, яка зазначає, що “перебуваючи в зовнішній щодо самої себе позиції, людина не лише думає, а й спостерігає за тим, як вона думає, не лише робить щось, а й контролює свої дії' [5, 43].

Із зазначеними процесами тісно пов'язаний i четвертий, інтелектуальний тип рефлексії, що характеризує, за визначенням В. Давидова, здатність особистості “виділяти, аналізувати і співвідносити з предметною ситуацією власні діі” $[3,687]$. По відношенню до доктора філософії така рефлексія означає осмислення і переосмислення ним сутності та змісту своєї дослідницькоінноваційної діяльності, її пріоритетних цілей та завдань, а також використання відповідних цим задачам методів, способів, засобів, прийомів. Необхідність такої рефлексії є цінною, насамперед, у тих випадках, коли діяльність виходить зі звичного русла та/або в ній з'являються внутрішні протиріччя, що особливо характерно для інноваційного типу діяльності. При цьому, як зазначає В. Єлісєєв, “рефлексія як термінове втручання призводить до перебудови структурних зв'язків між складовими елементами діяльності"' $[4,24]$, а також до її переосмислення та створення інновацій як реакції на подолання суперечностей, які виникають в процесі вирішення професійних завдань.

Для цього типу рефлексії характерні такі якості особистості як самоствердження, самоактуалізація, самореалізація, які спрямовані на професійне самовдосконалення та професійний розвиток суб' єкта діяльності. Отже, констатуємо, що цей тип рефлексії здійснює перспективну функцію як такий, що спрямований на подальше професійне зростання доктора філософії.

Таким чином, у процесі виконання дослідницько-інноваційної діяльності, яка носить не лише індивідуальний, але й колективний характер, як правило, протікає у нових, невизначених умовах, супроводжується виникненням нестандартних ситуацій тощо, у доктора філософії виникає потреба щодо творчого переосмислення:

- свідомості (особистісний аспект);

- спілкування (комунікативний аспект);

- співробітництва (корпоративний аспект);

- змісту діяльності (інтелектуальний аспект)

та прийняття рішення щодо її реорганізації. У цьому i полягає сутність рефлексивноперспективного компоненту готовності до дослідницько-інноваційної діяльності, у процесі якої доктор філософії має виконувати такі функції як: “Я - контролер” (контрольна функція), “Я комунікатор” (аналітична функція), “Я координатор” (координаційна функція), “Я професіонал" (перспективна функція).

На рис.1 наведена структура цього компоненту, побудована нами за результатами проведених теоретичних розвідок.

Висновки i перспективи подальших досліджень. Підсумовуючи вищевикладене, робимо висновок, що рефлексивно-перспективний компонент готовності майбутнього доктора філософії до дослідницько-інноваційної діяльності передбачає наступні дії: усвідомлення самого себе як суб' єкта діяльності, своїх особливостей, здібностей, вчинків та того, як він сприймається іншими; переосмислення цілей, процесу та результатів своєї діяльності, виправлення помилок та пошук шляхів її вдосконалення; уявлення про внутрішній світ інших людей та аналіз причин їхніх 


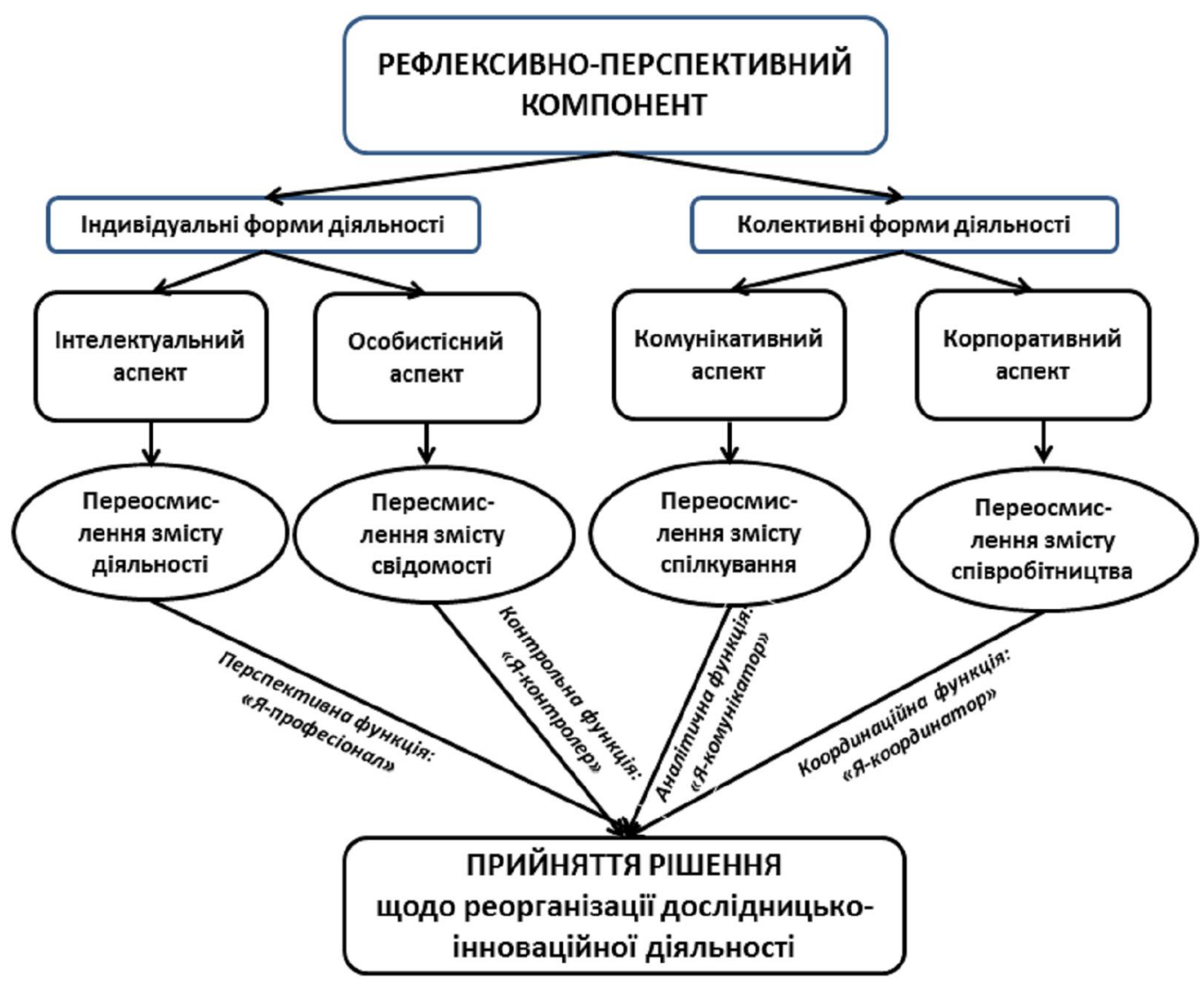

Рис. 1. Структура рефлексивно-перспективного компоненту готовності доктора філософії до дослідницько-інноваційної діяльності

дій; усвідомлення процесу перебігу спільної діяльності учасників колективного процесу та ухвалення відповідних рішень задля іiї координації та успішного виконання, а також прагнення до постійного самовдосконалення, професійного зростання та розвитку.

Перспективою наших подальших досліджень $€$ розробка структурно-функціональної моделі формування готовності майбутнього доктора філософії до дослідницько-інноваційної діяльності.

\section{ЛІТЕРАТУРА}

1. Бодалев А. А. Личность и общение. М.: Международная педагогическая академия, 1983. - 272 с.

2. Выготский Л. С. Собрание сочинений: В 6 т. Т. 4. М.: Педагогика, $-1984 .-433$ с.

3. Давыдов В. В. О двух основных путях развития мышления школьников. В кн.: Материалы IV Всесоюзного съезда Общества психологов СССР. Тбилиси, - 1971. - С. 686-687.

4. Елисеев В. К. Становление и развитие рефлексивной культуры учителя как субъекта педагогической деятельности. Автореф... дисс. д. пед. н.: спец. 13.00.08. - М.: МГПУ, 2005. $42 \mathrm{c}$.

5. Марусинець М. Професійна діяльність педагога: рефлексивний аспект. Психологопедагогічні проблеми сільської школи. - 2012. № 43(1). - С. 39 - 45 .

6. Полякова Г. Показники педагогічної творчості вчителя. Психолог. - 2006.- № 35. C. 3-5.

7. Порядок підготовки здобувачів вищої освіти ступеня доктора філософії та доктора наук у закладах вищої освіти (наукових установах): Постанова Кабінету Міністрів України від 23 березня 2016 p. № 261. URL: http:// zakon5.rada.gov.ua/laws/show/261-2016-\%D0\%BF

8. Смирнова Е. В., Сопиков А. П. Рассуждение о рассуждениях (рефлексивность сознания личности). В кн.: Социальная психология личности. Л., - 1973.- С. 140-149.

9.Степанов С.Ю.,СеменовИ.И.,НовиковаЕ. Р. Типы и функции рефлексии в организации принятия решения оператором. - В кн.: Проблемы инженерной психологии. Вип. 2. Л., - 1984. C. $127-129$. 
10. Степанов С. Ю., Семенов И. Н. Психология рефлексии: проблемы и исследования. Вопросы психологии. - 1985. - № 3. - С.31-40.

11. Філософський енциклопедичний словник / за ред. В. І. Шинкарук. Київ: Абрис, 2002.- 742 с.

12. Щедровицкий Г. П. Коммуникация, деятельность, рефлексия. В кн.: Исследования речемыслительной деятельности. Алма-Ата, 1974.- C. 12.

\section{REFERENCES}

1. Bodalev, A. A. (1983). Lychnostj y obshhenye [Personality and communication]. - Moscov: Mezhdunarodnaja pedagogicheskaja akademija, 272 p. [in Russian].

2. Vygotskij, L. S. (1984). Sobranie sochinenij [Collected works]. Moscov: Pedagogika, Vol.4, 433 p. [in Russian].

3. Davydov, V. V. (1971). O dvuh osnovnyh putjah razvitija myshlenija shkolnikov [About two main ways of developing schoolchildren's thinking]. Materials of the Fourth All-Union Congress of the Society of Psychologists. Tbilisi. pp.686-687. [in Russian].

4. Eliseev, V. K. (2005). Stanovlenie i razvitie refleksivnoj kultury uchitelja kak subekta pedagogicheskoj dejatelnosti [Formation and development of the teacher's reflective culture as a subject of pedagogical activity]. Extended abstract of Doctor's thesis. Melitopol, 42 p. [in Russian].

5. Marusynecj, M. (2012). Profesijna dijaljnistj pedaghogha: refleksyvnyj aspect [Professional activity of the teacher: reflexive aspect]. Psychological-pedagogical problems of rural school. No.43(1), pp. 39 - 45. [in Ukrainian].

6. Poljakova, Gh. (2006). Pokaznykypedaghoghichnoji tvorchosti vchytelja [Indicators of pedagogical creativity of the teacher]. Psychologist. No.35, pp. 3-5. [in Ukrainian].

7. Porjadok pidghotovky zdobuvachiv vyshhoji osvity stupenja doktora filosofiji ta doktora nauk u zakladakh vyshhoji osvity (naukovykh ustanovakh) (2016). [The procedure of preparation of applicants for higher education for the degree of doctor of philosophy and doctor of sciences in institutions of higher education (scientific institutions)]. Resolution of the Cabinet of Ministers of Ukraine dated March 23, 2016 No. 261. Retrieved from: http://zakon5.rada.gov.ua/laws/show/ 261-2016-\%D0\%BF [in Ukrainian].

8. Smirnova, E. V. \& Sopikov, A. P. (1973). Rassuzhdenie o rassuzhdenijah (refleksivnost soznanija lichnosti) [Argumentation of reasoning (reflexivity of consciousness of personality)]. Social psychology of personality. pp. 140-149. [in Russian].

9. Stepanov, S. Ju., Semenov, I. I. \& Novikova, E. R. (1984). Tipy i funkcii refleksii v organizacii prinjatija reshenija operatorom [Types and functions of reflection in the organization of decision-making by the operator]. Problems of engineering psychology. Vol. 2, pp.127-129. [in Russian].

10. Stepanov, S. Ju. \& Semenov, I. N. (1985). Psihologija refleksii: problemy i issledovanija [Psychology of reflection: problems and research]. Questions of psychology. No.3, pp. 31-40. [in Russian].

11. Shynkaruk, V.I.(2002). Filosofsjkyj encyklopedychnyj slovnyk [Philosophical Encyclopedic Dictionary]. Kyiv: Abrys, 742 p. [in Ukrainian].

12. Shhedrovickij, G. P. (1974). Kommunikacija, dejatelnost, refleksija [Communication, activity, reflection]. Studies of verbal thinking. Alma-Ata, p.12. [in Russian].

Стаття надійшла до редакції 20.12.2018

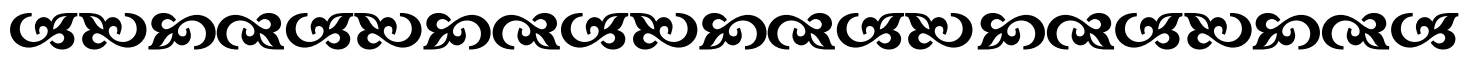

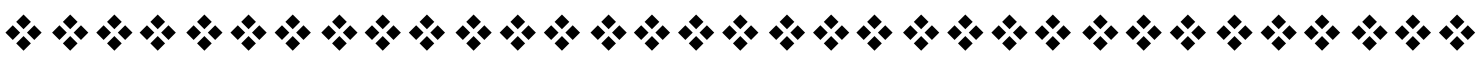

"Не важливо, що саме ти робиш, важливо, щоби все, до чого ти торқаєшся, змінювало фборму, ставало не тақим, якраніше, щоб у нъому залишалася частинка тебе самого".

Рей Бредбері

америқанський письменник

“Дише преқрасне буде радісне, вічне і иінне у всі часи".

Оскар УУайльд

ірландський поет, драматург

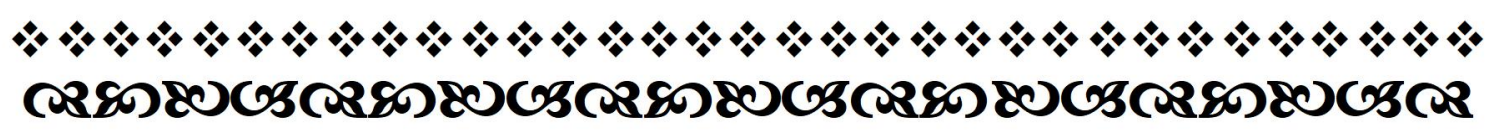

